\title{
Forma e Estilo no Ensino da Língua: variação e uso linguísticos
}

\author{
Form and Style in the Teaching of Language: \\ LINGUISTICS VARIATION AND USAGE
}

\section{Geraldo José Rodrigues LISKA * Celso FERRAREZI JÚNIOR **}

Resumo: A aceitação de conceitos descritivo-referenciais de objetos direciona as formas de análise e perscrutação desses mesmos objetos. Isso não é diferente nos estudos linguísticos. Aceitar que línguas são sistemas socializados e culturalmente determinados de representação de mundos e seus eventos (FERRAREZI Jr., 2010) implica aceitar que as línguas mudam conforme ocorrem mudanças culturais e sociais em uma comunidade linguística. Neste artigo, investigamos a motivação para a produção discursiva não como representação de conceitos, mas como processo de valorização da forma. Tratamos da produção do discurso-forma como meio de consecução de objetivos comunicativos e sociais e não do discurso referencial, baseado no conteúdo e nos sentidos decorrentes da referenciação. Ou seja, em vez da produção dos sentidos, o que está em jogo na fala objeto de nossa análise é o impacto das formas produzidas e da forma de produção, cujos sentidos referenciais o próprio autor assume desconhecer. Pretendemos, com isso, ressaltar na sala de aula o estudo da língua por meio de fatores sociais e

\footnotetext{
* Doutorando em Estudos Linguísticos (Área: Linguística Aplicada. Linha: Ensino do Português) pela Universidade Federal de Minas Gerais (UFMG). Secretário Executivo da Universidade Federal de Alfenas - Unifal. Contato: geraldo.liska@unifal-mg.edu.br. ** Doutor em Linguística - Semântica pela Universidade Federal de Rondônia (1998). Pós-Doutor em Semântica pela Universidade Estadual de Campinas (2005). Docente do Instituto de Ciências Humanas e Letras da Universidade Federal de Alfenas - Unifal, Alfenas-MG. Contato: celso.ferrarezi@unifal-mg.edu.br.
} 
culturais, levando em conta as diversas construções morfológicas e sintáticas permitidas na interação entre sujeito, língua e mundo.

Palavras-chave: Variação linguística e social. Estilística. Discurso. Escolhas lexicais. Ensino de gramática.

Abstract: Acceptance of descriptive -referential concepts of objects directs forms of analysis and thorough research these same objects. This is no different in linguistic studies. Accept that languages are socialized systems and culturally determined representation of events and their worlds (FERRAREZI, 2010), implies accepting that languages change as cultural and social changes occur in a linguistic community. In this article, we investigate the motivation for discourse production than as a representation of concepts, but as a process of valuing form. We deal with the production of discourse - shape means of achieving communicative and social goals and not the referential speech based on content and meanings arising from the referral. That is, instead of the production of meanings, what is at stake in talks object of our analysis is the impact of forms produced and the way of production, whose references senses the author assumes unaware. We intend, therefore, to emphasize in the classroom language study through social and cultural factors, taking into account the morphological and syntactic constructions allowed in the interaction between subject, language and world.

Keywords: Linguistic and social variation. Stylistics. Speech. Lexical choices. Grammar teaching.

\section{Introdução}

A aceitação de conceitos descritivo-referenciais de objetos direciona as formas de análise e perscrutação desses mesmos objetos. Isso não é diferente nos estudos linguísticos. Aceitar que línguas são sistemas socializados e culturalmente determinados de representação de mundos e seus eventos (FERRAREZI Jr., 2010) implica aceitar que as línguas mudam conforme ocorrem mudanças culturais e sociais em uma comunidade linguística. 
Há muita discussão sobre a produção e a representação de conceitos e suas formas, que englobam texto e discurso, fatores cognitivos e lexicais do processamento da linguagem e estudos acerca da variação e mudança linguísticas relacionadas à cultura. Este parece ser um tema interminável e sobre o qual pouca homogeneidade deve ser esperada. Torna-se importante, portanto, delimitar um ponto de vista e direcionar a investigação a partir de uma perspectiva mais restrita.

Em função disso, neste artigo investigamos a motivação para a produção discursiva não como representação de conceitos, mas como processo de valorização da forma. Tratamos da produção do discursoforma como meio de consecução de objetivos comunicativos e sociais e não do discurso referencial, baseado no conteúdo e nos sentidos decorrentes da referenciação. Ou seja, em vez da produção dos sentidos, o que está em jogo na fala objeto de nossa análise é o impacto das formas produzidas e da forma de produção, cujos sentidos e referências o próprio autor assume desconhecer.

Logo em princípio, isso pode levantar um questionamento: tendo em vista que o próprio criador das formas não sabe seu sentido e lhes nega um conteúdo referencial, como pode um falante dizer e não dizer? Estamos lidando então com um caso em que a significação acontece no processo, em uma construção discursiva puramente baseada na forma socialmente valorizada, desprovida de sentido, e não no conteúdo do discurso, nem no próprio discurso enquanto produto final comunicativo. A produção de um discurso in absentia de sentido pode parecer tema para a retórica ou para a estilística, pois as gramáticas recomendam que tudo aquilo que foge à norma, ao modo ideal da língua, refere-se aos recursos retóricos e/ou estilísticos de expressão. Porém cremos que a questão aqui é mais do que estilística: é sociocomunicativa e abrange dimensões muito complexas da produção da fala como parte da construção cultural de uma comunidade.

Para demonstrar isso, analisaremos a construção de sentidos não referenciais, mas socialmente representativos, no discurso de um radialista ${ }^{1}$. Assim, esperamos mostrar como se materializam as relações sociais de trocas

${ }^{1}$ Disponível em <http:/ / migre.me/qHdDY>. Acesso em: 11 dez 2013. 
linguísticas em casos como esse, por meio de estruturas linguísticas que se focam muito mais nos efeitos estilísticos que produzem do que propriamente no uso costumeiro das palavras.

Pretendemos, com isso, ressaltar na sala de aula o estudo da língua por meio de fatores sociais e culturais, levando em conta as diversas construções morfológicas e sintáticas permitidas na interação entre sujeito, língua e mundo.

\section{Escolha e Criação Lexical na Estilística da Língua}

Duas formas costumeiramente aceitas de direcionar o estudo das palavras são partir, de um lado, da palavra para os seus sentidos e referentes, e, do outro, de um significado ou conceito (ou uma entidade referencial) para as diferentes palavras ou itens lexicais que o podem designar (SILVA, 2006a), conforme a Figura 1.
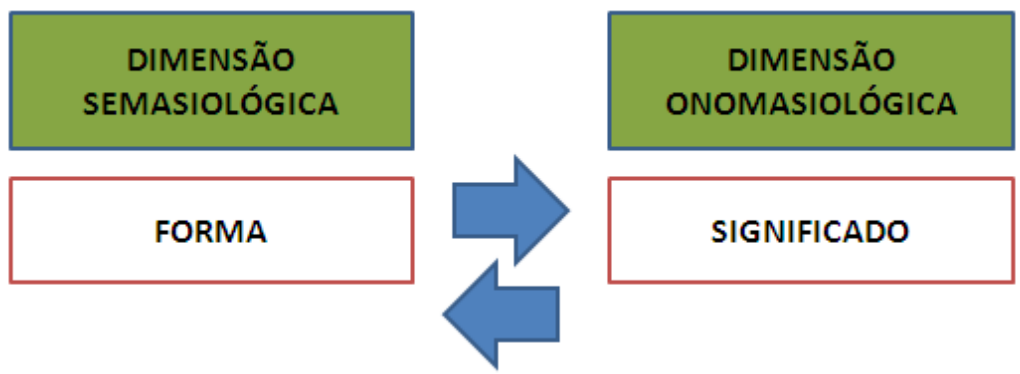

Figura 1

Dessa forma, ao analisar as mudanças pelas quais a língua passa, temos o desenvolvimento de novos sentidos de determinada palavra, isto é, a mudança semasiológica, e a expressão de determinado conceito, previamente lexicalizado ou não, por um novo ou diferente item lexical, isto é, a mudança onomasiológica. Essas mudanças têm a função de atribuir um conceito ou uma referência a uma nova forma ou a um novo sentido, assumindo a finalidade denominativa dos processos de formação de palavras, ou, ainda, podem ser motivadas pela busca de maior expressividade no discurso, assumindo a finalidade estilística desse processo de criação lexical. 
Tradicionalmente, essas mudanças são encaradas como resultado natural do efeito do tempo sobre a língua (como afirmava Saussure (2012)). Aqui, como já antecipado, defendemos que elas são resultado de mudanças culturais na comunidade de fala as quais implicam a necessidade de adaptação da língua para sua expressão.

As escolhas lexicais se realizam a partir de modelos e representações mentais construídos subjetivamente pelo indivíduo por meio de acontecimentos vivenciados e experiências cotidianas. Mesmo que esses modelos e representações mentais se realizem de modo subjetivo, "podem ser afetadas pela cognição social, pelas crenças coletivas traduzidas na ideologia" (GIL, 2007, p. 3). As escolhas lexicais, então, estão diretamente associadas às atitudes, crenças e ideologias dos falantes.

A escolha lexical é uma das propriedades ou estruturas do discurso mais fortemente orientadas para a estrutura social e mais relevantes para o estudo dos aspectos sociais da linguagem, pois está diretamente associada a crenças, atitudes e ideologias dos interlocutores, o que significa que aponta diretamente para a realidade e para o entendimento de mundo dos enunciadores. (GIL, 2007, p. 4).

Brait (2003) afirma que a análise da dimensão persuasiva do discurso deve levar em conta traços que identifiquem as intenções do enunciador, como a manipulação que ele pretende exercer sobre o outro; a exploração do jogo de imagens que ele constrói sobre si mesmo; os efeitos de sentido ocasionados no texto; e a interação discursiva entre os interlocutores.

Ao realizar seu discurso em uma rádio local (Anexo 1), Carro Velho busca a composição de palavras ou a renovação de sentidos em material lexical já existente, a fim de atingir prestígio linguístico. Ele cria seu discurso na direção de uma "fala bonita", como popularmente concebida, repleta de "palavras difíceis", uma estrutura concebida por sua "boniteza" muito mais do que por seu conteúdo. Há nisso uma espécie de esperteza equívoca, nos moldes de equivocidade concebidos por Epstein (1993), que burla as regras sociais ao mesmo tempo em que recorre a elas em busca de "homologação" e prestígio, permitindo construir um discurso em que a forma em si expressa muito mais valores do que um pretendido conteúdo. 
Veremos que, embora seja de costume o estudo das palavras na orientação semasiológica ou onomasiológica, as criações lexicais dele não se orientam para nenhuma delas, pois o real significado está na intenção de uma criação que busca a imitação de um padrão estilístico muito mais do que a construção de argumentos ou referenciações, e não no produto, seja este orientado para uma nova forma ou um novo sentido. Muitas de suas palavras não têm qualquer intenção referencial, foram criadas especialmente para dar status a seu discurso, mais em função da ideia de "intelectualidade" que um vocabulário "difícil” passa. Assim, encontram-se em um domínio que intersecciona o linguístico e o extralinguístico de caráter cultural. Mesmo que essas novas formações sejam efêmeras e não façam parte dos usos da comunidade linguística, elas se comportam como um dos fatores que evidenciam um estilo próprio de o autor se expressar. Embora seja essa manipulação da linguagem objeto de estudo da Estilística, como afirma Cardoso (2004, p. 148):

Um dos objetivos da estilística é justamente analisar a escolha feita, verificando-se de que maneira se consegue com ela efeitos estéticos e expressividade e, sobretudo tentando-se chegar à intenção do enunciador por meio do estilo encontrado em seu texto.

No discurso de Carro Velho, ultrapassa os limites meramente estilísticos e adentra questões de ordem socioculturais profundas. Por exemplo, o fato de que o ouvinte popular presumido de um discurso verdadeiramente difícil e intelectualizado dispensa a compreensão de seu conteúdo. Carro Velho não joga apenas com a criação de palavras ou sentidos, mas também aposta na conivência de um ouvinte que não faz questão de compreender a "fala difícil", desde que ela tenha uma aparência convincente de discurso "elitizado".

Sobre a intencionalidade da escolha lexical, Cardoso (2004) também afirma que, em todo ato de comunicação, existe algo além de simplesmente transmitir a mensagem, mesmo que ela seja referencial, objetiva, pois há com ela "um aspecto intencional, seja um desejo de impressionar o destinatário, seja um desejo de marcar uma posição" (CARDOSO, 2004, p. 148).

É justamente nesse desejo de marcar uma posição que parece se estruturar o discurso de Carro Velho. As novas formações semânticas e 
formais, além de evidenciarem seu próprio estilo de fala, mostram como são as crenças e as atitudes dos falantes em relação à própria língua. A tentativa de ele usar palavras "difíceis" se fundamenta na crença de que existe um modo prestigioso de falar. Esse modo prestigioso da fala, como Carro Velho o constrói, baseia-se muito mais no impacto estilístico da fala do que naquilo que ela pode transmitir referencialmente. É claro que a intenção exagerada de imitar uma forma valorizada da língua será ridícula quando percebida por aquele que já domina verdadeiramente essa forma e isso é o que faz o discurso dele ser engraçado para muitos. Porém essa graça é misturada por admiração para muitos outros que não dominam a forma de prestígio. Essa destreza discursiva de Carro Velho permitiu o direito a voz e a espaço social a um indivíduo que vendia leite na rua, de porta em porta, em um carro velho, sem qualquer possibilidade de prestígio.

\section{Estilo, Segurança e Atitude para a Formação do Discurso}

Para Calvet (2002, p. 65), "existe todo um conjunto de atitudes, de sentimentos dos falantes para com suas línguas, para com as variedades de línguas e para com aqueles que as utilizam". Na intenção de falar bem por meio de uma língua privilegiada, o falante comprova a existência de variantes desprestigiadas e a decorrência de uma série de preconceitos e estereótipos, nos quais as pessoas são julgadas pelo seu modo de falar, que circula entre as variantes diatópicas, diastráticas e diacrônicas. Esses estereótipos são consequência da noção de "uso correto" (bon usage) da língua, segundo a qual temos modos de falar que são consagrados como o "modo certo" e, de outro lado, os modos condenáveis. Para decidir entre a rejeição ou a aceitação de determinado modo da fala, os falantes usarão o que Calvet (2002) chama de "norma espontânea", "que os leva a decidir que forma deve ser proscrita, que outra deve ser admirada: não se fala assim, se fala assado" (CALVET, 2002, p. 68).

Embora o discurso do Carro Velho ocasione uma sensação de humor, porque é perceptível a tentativa de alcançar uma fala de elevado padrão linguístico, ele declara não se sentir questionado em seu modo de falar. Ele conseguiu construir sua própria norma, mesmo sabendo que a valorização da sua fala não chega ao modelo idealizado da língua e que, para muitos, é 
motivo de riso. Quando perguntado, em outra entrevista ${ }^{2}$, sobre o significado das suas palavras, ele afirma conhecer somente "rélpis" (répteis), que, segundo ele, seriam "animais que se arrastam" (sic), e "batráquio", que seriam "animais que pulam” (sic), palavras aprendidas na quarta série do antigo primário, a última que cursou em ambiente escolar formal. Essa declaração nos mostra que o importante, para ele, não é a relação de sentidos nas formações "pessoa rélpis" e "pessoa batráquio", mas sim a valorização das formas "rélpis" e "batráquio" em si, pela imagem de "palavra difícil" que transmitem. Ou seja, sua intencionalidade está direcionada a empregar um nível de linguagem de compreensão dificultada por meio de vocabulário restrito, léxico sofisticado e de difícil acesso, para passar a ideia de um discurso de alto padrão.

\section{Analisando o Objeto Discursivo}

Vemos que, deixando um pouco de lado as criações formais e semânticas, as variações fonéticas de Carro Velho são comuns entre os falantes do português e orientadas para a otimização da sua produção linguística, quanto à facilidade de articulação, resultado de processos lenitivos. No entanto, por razões culturais e socioeconômicas, elas tendem a gerar algum preconceito linguístico, porque, tradicionalmente, ensina-se que o português não padrão é uma variação inferior em relação ao português padrão, e não diferente dele. Muitos dos traços da fala do Carro Velho, que são engraçados por serem considerados "erros", encontram-se em outras línguas, como o yeísmo do $[K]>$ [j] em [fa'milja], por vezes produzida [fa'mi $\Lambda_{a}$ ] ou [fa'mia], "o que mostra que eles não são uma prova da "ignorância" ou da "deficiência mental" do nosso povo” (BAGNO, 1997, p. 202). Por isso mesmo, nos interessa aqui muito mais a produtividade lexical nesse discurso.

Para realizar um estudo das estruturas sociais e culturais que estão associadas à produção lexical, a fim de entendermos a motivação dessas escolhas lexicais em sua relação com a experiência individual acumulada culturalmente e com as práticas coletivas da linguagem, "é preciso transpor o estudo dicionarizado dos elementos lexicais e avaliá-los nas manifestações

${ }^{2}$ Disponível em <http://migre.me/qHdHC>. Acesso em: 11 dez. 2013. 
discursivas" (GIL, 2007, p. 1). Analisamos, então, alguns itens lexicais utilizados no discurso, por meio do critério lexicográfico ${ }^{3}$ :

No Quadro 1, temos as criações lexicais e novos usos de material lexical que favorecem o discurso de Carro Velho como produção de prestígio linguístico:

Quadro 1 - Criações lexicais e novos usos de material lexical existente no discurso de Carro Velho

\begin{tabular}{|c|c|c|c|}
\hline item lexical & $\begin{array}{l}\text { criação } \\
\text { formal }^{4}\end{array}$ & $\begin{array}{c}\text { criação } \\
\text { semântica }\end{array}$ & observações \\
\hline batráquio & & $\mathrm{x}$ & $\begin{array}{l}\text { Infere-se no discurso que a associação } \\
\text { semântica de 'batráquio' a 'pessoa' está } \\
\text { além do traço semântico de 'animais que } \\
\text { pulam' que o próprio autor atribui ao } \\
\text { termo. Percebemos, nessa formação, o } \\
\text { mesmo que acontece em 'pessoa rélpis' e } \\
\text { 'respeito tecnológico': o falante se } \\
\text { preocupa com a valorização das formas, e } \\
\text { não com a relação de sentidos. Infere-se do } \\
\text { contexto que se trata de uma palavra de } \\
\text { traço semântico [+positivo]. }\end{array}$ \\
\hline
\end{tabular}

${ }^{3}$ Por meio desse critério, são considerados neologismos lexicais as unidades que não estejam registradas em uma seleção de dicionários de língua. Para tanto, foram adotados como corpus de exclusão três importantes dicionários brasileiros: Dicionário Honaiss da língua portuguesa (2001), Novo Aurélio século XXI: o dicionário da língua portuguesa (2005) e Michaelis Português - moderno dicionário da língua Portuguesa (1998). Utilizamos ainda o Vocabulário Ortográfico da Lingua Portuguesa online, da Academia Brasileira de Letras, disponível em < http://migre.me/qHdjj> (acesso em: 20 dez 2013) e o iDicionário Aulete, da Lexikon Editora Digital, então disponível em $<$ http://migre.me/qHdLk>, acesso em 20 dez 2013. Atualmente, o Dicionário Aulete pode ser acessado em: <http://migre.me/qHdO4>.

4 "A expressão de determinado conceito, previamente lexicalizado ou não, por um novo ou diferente item lexical, isto é, a mudança onomasiológica" (SILVA, 2006, p. 87). Ressaltamos que, entre as variações onomasiológicas, temos as extensões semasiológicas, pois entende-se que todas as mudanças semasiológicas são também onomasiológicas, principalmente quando se leva em conta a iconicidade e o isomorfismo da palavra.

5 "qualquer transformação semântica manifestada em um item lexical" (ALVES, 2004). 


\begin{tabular}{|c|c|c|c|}
\hline cabriocárica & $\mathrm{x}$ & & $\begin{array}{l}\text { Registro não encontrado. Infere-se do } \\
\text { contexto que se trata de uma palavra de } \\
\text { traço semântico [+ positivo]. }\end{array}$ \\
\hline strambólica & & $\mathrm{x}$ & $\begin{array}{l}\text { Todos os registros apontam como } \\
\text { sinônimo de 'extravagante'. No entanto } \\
\text { percebemos, no discurso, o uso da palavra } \\
\text { no sentido de apreciar, e não depreciar } \\
\text { alguém. Temos então o sentido invertido e } \\
\text { orientado para o traço [+ positivo]. }\end{array}$ \\
\hline estrogonoficamente & $\mathrm{x}$ & & $\begin{array}{l}\text { Conforme Basílio (2007), a esmagadora } \\
\text { maioria dos advérbios é formada a partir } \\
\text { do acréscimo do sufixo - mente a adjetivos. } \\
\text { A forma em -mente apresenta um tom mais } \\
\text { neutro e formal ao discurso. Ou seja, } \\
\text { temos a valorização do sufixo sobre a } \\
\text { palavra ligada a ele, escolhida pela sua } \\
\text { forma, e não pelo seu sentido. }\end{array}$ \\
\hline inoxidável & & $\mathrm{x}$ & $\begin{array}{l}\text { Todos os registros apontam para 'que não } \\
\text { se oxida ou enferruja', devido ao acréscimo } \\
\text { de -in, passando a significar [-oxidável]. } \\
\text { No entanto, não parece que a intenção de } \\
\text { Carro Velho ao usar 'pessoa inoxidável' } \\
\text { seja querer dizer 'pessoa que não oxida'. } \\
\text { Logo à frente, no texto, ele afirma: "pessoa } \\
\text { inoxidável, quer dizer, uma pessoa } \\
\text { brilhante". }\end{array}$ \\
\hline mediocrático & & $\mathrm{x}$ & $\begin{array}{l}\text { Todos os registros apontam como } \\
\text { referente à 'mediocracia' (= "poder social e } \\
\text { político dirigido classe média"), no entanto } \\
\text { percebemos no discurso o uso da palavra } \\
\text { no sentido de apreciar alguém [+ positivo]. }\end{array}$ \\
\hline mediováigel & $\mathrm{x}$ & & $\begin{array}{l}\text { Registro não encontrado. Infere-se do } \\
\text { contexto que se trata de uma palavra de } \\
\text { traço semântico [+ positivo]. }\end{array}$ \\
\hline respeito tecnológico & $\mathrm{x}$ & & $\begin{array}{l}\text { Percebemos nessa formação o mesmo que } \\
\text { acontece em "pessoa rélpis" e "pessoa } \\
\text { batráquio": o falante se preocupa com a } \\
\text { valorização das formas, e não com a } \\
\text { relação de sentidos. }\end{array}$ \\
\hline subjestivamente & $\mathrm{x}$ & & $\begin{array}{l}\text { Provavelmente motivado por } \\
\text { "subjetivamente". Infere-se do contexto } \\
\text { que se trata de uma palavra de traço } \\
\text { semântico [+positivo], cuja associação } \\
\text { semântica de "subjestivamente qualificado" } \\
\text { a "pessoa" está além do traço semântico de } \\
\text { "qualificado de modo subjetivo", } \\
\text { conforme a ideia da associação. }\end{array}$ \\
\hline
\end{tabular}




\section{A Estilística da Língua entre a Inovação Lexical e o "Erro"}

Discursos como o de Carro Velho não são unanimidade. Eles são encarados como uma peça de humor por algumas pessoas, mas geram uma negativa sensação de ridículo em outras. Para exemplificar isso, podemos recorrer ao relato de pessoas que são referência no ensino do português no Brasil e que contribuem para a ideia da língua de prestígio, como o professor Pasquale Cipro Neto. Numa de suas publicações para a Alô Escola, ele afirma:

Muitas pessoas no Brasil dizem "pobrema". A pronúncia oficial, no entanto, deve ser sempre como se grafa a palavra: pro-ble-ma. [...] A pessoa faz essa alteração muitas vezes em decorrência do seu meio cultural. Como vimos, o problema tem explicação científica e há solução para ele. A pessoa pode fazer um tratamento para aprender a empostar a voz, a pronunciar melhor as palavras. (CIPRO NETO, [s.d.], grifo nosso).

$\mathrm{Na}$ fala de Carro Velho, os mecanismos de variação que levaram "programa" a "pogama" se assemelham aos de "problema" > "pobrema". Conforme Cipro Neto, trata-se de um problema "com explicação científica" que pode ser solucionado com tratamento fonoaudiológico. Ele ressalta que ninguém pode ser discriminado por esse "problema", que tem nome: "dislalia ou distúrbio articulatório, antigamente era chamado de rotacismo"”.

Porém, a afirmação de Cipro Neto é absurda e altamente discriminatória. A pronúncia de uma palavra como aprendida em determinada comunidade (como "pobrema" ou "pograma") não tem qualquer relação com distúrbios fonoaudiológicos. Afirmar que a decorrência desse "problema" é o meio cultural em que a pessoa nasce e cresce, ou que ele seja fruto de uma disfunção de fala, é discriminação. Aliás, afirmar que o meio

${ }^{6}$ Cipro Neto está equivocado ao afirmar que o fato de as pessoas pronunciarem "probrema" em vez de "problema" se trata de distúrbio da fala, dislalia. Essa característica é uma variação linguística, não uma doença, e a ciência que explica essa variação linguística é a Sociolinguística, e não a Fonoaudiologia, como ele pretende. 
cultural interfere na vida da pessoa a ponto de ocasionar um "problema cientificamente explicável" [+ negativo / - positivo] na fala dela, e não uma variação [de traço ø, em relação a 'problema' (+) ou ‘solução' (-)], além de preconceito linguístico, é preconceito cultural ${ }^{7}$ disfarçado na forma de uma fala "prestigiosa" que recorre ao argumento da cientificidade para ocultar seu caráter ideológico.

De fato, como afirma Possenti (1998), para que o humor aconteça, além da criatividade, é preciso que haja um "solo" fértil de problemas frutos da manifestação social que envolve assuntos polêmicos e estereotipados, na maioria das vezes ligados ao preconceito. Falar de uma forma que seja diferente da norma culta pode resultar no preconceito linguístico, que, nesse caso, seria apenas mais um dos ingredientes na receita do humor. Porém, até nisso Carro Velho parece ter uma compreensão cabal dos efeitos de seu discurso. Ao atribuir-lhe essa feição caricatural, ele consegue obter a aprovação da classe social à qual pertence e contar com a conivência bem humorada de uma parte significativa daqueles que realmente dominam o discurso prestigioso.

Conforme Bourdieu (1998), a competência linguística legitima o indivíduo em determinado grupo. Isso se baseia na ideia de que a língua é como um produto a ser socialmente "comercializado". Quem a domina tem o que oferecer, uma "boa mercadoria", lançando todos os outros que não têm esse produto valorizado (domínio da língua) em um segundo plano, inferior. Para Bourdieu (1998), essa valorização deve acontecer quando observamos as práticas e condições sociais da linguagem.

No entanto, até 1996, o ensino do português se resumia à memorização mecânica de regras gramaticais ou das características de determinado movimento literário, encaixava-se "num período em que ensinar gramática era algo obsoleto e inoperante” (SOUZA; ARÃO, 2009, p. 71). As reflexões sobre isso refletiram nos Parâmetros Curriculares Nacionais - Português (BRASIL, 1998, 2000). Além disso, o estudo dos efeitos de sentido ocasionados por escolhas linguísticas que fogem à norma devem ser estudados pela retórica e não cabem ao ensino da gramática.

O conhecimento "científico" valorizado em detrimento do conhecimento "popular" - por exemplo, o desprezo por práticas medicinais naturais e tradicionais em favor de medicamentos químicos industrializados; ou a valorização da cultura transmitida por escrito em detrimento da cultura transmitida oralmente (BAGNO, 1997, p. 204). 
Em resumo, a retórica é um conjunto de desvios suscetíveis de autocorreção, isto é, que modificam o nível normal de redundância da língua, transgredindo regras, ou inventando outras novas. O desvio criado por um autor é percebido pelo leitor graças a uma marca, e em seguida reduzido graças à presença de um invariante. $\mathrm{O}$ conjunto dessas operações, tanto as que se desenvolvem no produtor como as que têm lugar no consumidor, produz um efeito estético específico, que pode ser chamado ethos e que é o verdadeiro objeto da comunicação artística. A descrição completa de uma figura de retórica deve então obrigatoriamente comportar a de seu desvio (operações constitutivas do desvio), a de sua marca, a de seu invariante e a de seu ethos. (MARTINS, 2000, p. 66-67).

Ou seja, valorizava-se a forma da língua, e não o uso dela, embora ainda seja comum nos livros didáticos a maior parte do estudo da língua ser dedicada à estrutura gramatical ${ }^{8}$. Provavelmente ainda seja esse o motivo de o prestígio recair sobre aquele que domina a gramática da "língua difícil", como sinônimo de elevada competência linguística.

Assim, se no Quadro 1 apresentamos os elementos que favorecem o discurso de Carro Velho como uma fala prestigiosa, neste outro os registros fonoestilísticos condenam sua fala em relação à norma, mas são comuns em variantes não padrão do português, o que o aproxima dos falantes "comuns" da língua.

${ }^{8}$ Conforme evidenciado com a análise dos livros didáticos na dissertação de mestrado "O humor da palavra e o desenvolvimento da competência lexical: Análise de livros didáticos de português dos anos finais do ensino fundamental”, defendida por um dos autores deste artigo, na Faculdade de Letras da Universidade Federal de Minas Gerais, em 2013. 


\section{Quadro 2 - Registros fonoestilísticos do discurso de Carro Velho}

\begin{tabular}{|c|c|c|}
\hline item lexical & $\begin{array}{l}\text { transcrição } \\
\text { fonética }\end{array}$ & observações \\
\hline educô & [edu'ko] & $\begin{array}{l}\text { Trata-se também de um caso de assimilação, em que o que era } \\
\text { escrito e pronunciado OU em pouco tempo passou a ser } \\
\text { pronunciado apenas Ô. Embora se escreva pouco, louro, roupa, } \\
\text { fala-se ['poku], ['loru] e ['Ropa], respectivamente. (BAGNO, } \\
\text { 1997). }\end{array}$ \\
\hline fazeno & $\begin{array}{l}\text { [fa'mia }] \\
\text { [fa'zẽnu }]\end{array}$ & $\begin{array}{l}\text { É um caso de assimilação do }[\lambda] \text { pelo }[\gamma] \text {, em que a dificuldade ao } \\
\text { pronunciar a consoante }[\lambda] \text { faz com que o falante a substitua pelo } \\
\text { som mais próximo }[\gamma] \text { (BAGNO, 1997) } \\
\text { É um caso de assimilação do [d] pelo [n]. Assim como falando, } \\
\text { que passou a [fa'lẽnu]' (BAGNO, 1997). }\end{array}$ \\
\hline levantano & [levẽ'tẽnu] & $\begin{array}{l}\text { E um caso de assimilação do [d] pelo [n]. Assim como falando, } \\
\text { que passou a [fa'lẽnu]' (BAGNO, 1997). }\end{array}$ \\
\hline lídel & {$[\mathrm{l} \gamma \mathrm{d} \varepsilon \mathrm{w}]$} & $\begin{array}{l}\text { Pode-se afirmar que se trata de um caso de lambdacismo }{ }^{10} \text {, assim } \\
\text { como ['gawfu]. Como se deu na história da língua: o provençal } \\
\text { [pa'per] }>\text { [pa'p\&w], [flor] }>\text { [frow] (SILVA, 2006b). }\end{array}$ \\
\hline ninhuma & [ni’’ũma] & $\begin{array}{l}\text { Conforme Bagno (1997), trata-se de harmonização vocálica, em } \\
\text { que a presença de }[\gamma] \text { e de }[\mathrm{u}] \text { na sílaba tônica faz com que as } \\
\text { vogais átonas pretônicas escritas [e] e }[\mathrm{o}] \text { se reduzam e sejam } \\
\text { pronunciadas }[\gamma] \text { e }[\mathrm{u}] \text {. }\end{array}$ \\
\hline & & Conforme Costa (2007), trata-se de um rotacismo em que a \\
\hline pogama & [po'gẽma] & $\begin{array}{l}\text { "sequência de líquidas provocaria a dissimilação do [l] em }[\mathrm{r}] \text { e de } \\
{[\mathrm{r}] \text { em }[\varnothing] \text {, como, por exemplo, a realização de 'problema' por }} \\
\text { "pobrema" (p. 7). }\end{array}$ \\
\hline rélpis & ['rewpyz] & 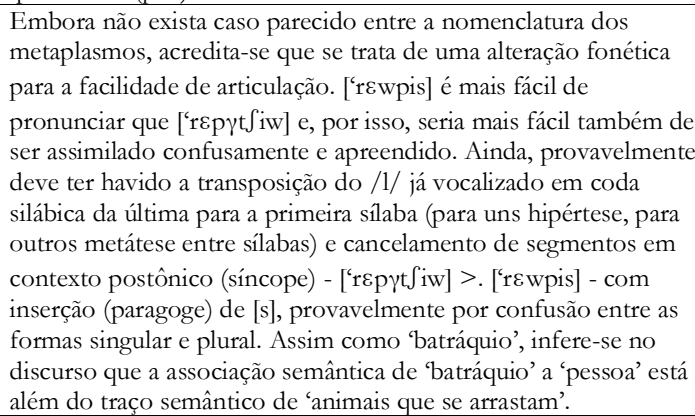 \\
\hline
\end{tabular}

${ }^{9}$ Deve-se observar que não só a troca de /1/ por tepe ocorre ao longo toda a história da língua, mas também é constante a instabilidade de $/ K /$, ora cancelado, como em

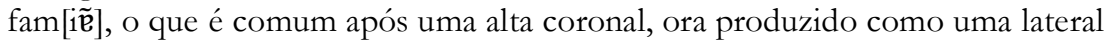
palatalizada (famí[lĩe] $)$, a variante mais produtiva na fala de indivíduos de todos os níveis de escolaridade, ora como uma lateral alveolar (mu[le]) ou como iode (mu[je]).

${ }^{10}$ Por terem sons próximos, as letras "l" e " $\mathrm{r}$ " acabam se misturando durante a trajetória diacrônica e sincrônica de modificação da língua, uma como constritiva lateral alveolar sonora e a outra como constritiva vibrante alveolar sonora, respectivamente (SILVA, 2006b). 


\begin{tabular}{|c|c|c|}
\hline simpricidade & [sĩpr $\gamma$ si'dad3i] & $\begin{array}{l}\text { Provavelmente motivado por 'retumbante'. Infere-se do contexto } \\
\text { que se trata de uma palavra de traço semântico [+ positivo], cuja } \\
\text { associação semântica de 'retumbante' a 'pessoa' está além do } \\
\text { traço semântico de 'que produz som estrondoso', definição na } \\
\text { maioria dos registros. } \\
\text { É um caso de rotacismo, em que há neutralização de uma líquida } \\
\text { lateral por uma líquida vibrante em sílabas do tipo } \\
\text { consoante+consoante+vogal, como, por exemplo, ['bluza] por } \\
\text { ['bruza]. (BAGNO, 1997). }\end{array}$ \\
\hline
\end{tabular}

Quando Dias Gomes criou o discurso de Odorico Paraguaçu, em "O Bem-Amado", havia uma intencionalidade específica e, como ressaltamos, recuperar os motivos e as finalidades que produziram os enunciados é importante para chegar à significação textual. Existe a conexão entre a significação e a intenção (SEARLE, 1991). As formações neológicas (por meio das subversões de itens lexicais já existentes) na fala do prefeito são uma demonstração de um suposto domínio sobre a língua, de seu "falar bem”. Dessa forma, o político faz uso do produto linguístico para conquistar seus eleitores, pois quem mostra ter conhecimento de um modo prestigioso da fala terá prestígio sobre falantes de outras variações. Temos vários exemplos:

(1) Quem é que pode viver em paz mormentemente sabendo que, depois de morto, defunto, vai ter que defuntar três léguas pra ser enterrado? (GOMES, 1992, p. 26-27, grifo nosso).

(2) Agoramente já investido no cargo de Prefeito, aqui estou para receber a confirmação, ratificação, a autentificação e por que não dizer a sagração do povo que me elegeu. (GOMES, 1992, p. 31, grifo nosso).

(3) Botando de lado os entretantos e partindo pros finalmentes, é uma alegria poder anunciar que prafentemente vocês já poderão morrer descansados, tranqüilos e desconstrangidos, na certeza de que vão ser sepultados aqui mesmo, nesta terra morna e cheirosa de Sucupira. (GOMES, 1992, p. 31, grifo nosso). 
(4) Mas o acontecido pratrasmente não conta. (GOMES, 1992, p. 66, grifo nosso).

Essas formações sufixais em -mente parecem ter os mesmos propósitos de 'estrogonoficamente', lembrando o que Basílio (2007) diz sobre a contribuição desse sufixo para a neutralidade e a formalidade do discurso. No entanto, os sentidos das formas subversas de 'mormentemente', 'agoramente', 'prafrentemente' e 'pratrasmente' são imprescindíveis para a significação, o que não acontece com 'estrogonoficamente', pois, conforme descrito, infere-se que a intenção ao usar essa palavra no discurso está ligada à sua forma, e não à associação metafórica da comida ou das características dela a uma pessoa. Ou seja: se comparada à fala construída por Dias Gomes para Odorico Paraguaçu, a fala de Carro Velho avança vários pontos no que tange à criação estilística: enquanto aquele recorria à manutenção de elementos significativos, na composição das palavras, para expressar a sensação de fala prestigiosa, este abre mão desses elementos e conta apenas com a forma para obter o mesmo resultado de prestígio.

No mundo acadêmico encontramos muitas pesquisas que abordam os neologismos estilísticos na literatura, criações lexicais estritamente relacionadas à expressividade literária.

A partir do século XIX, ficcionistas e poetas, de Portugal e do Brasil, passaram a explorar mais intensamente o léxico virtual, reunindo radicais e afixos em novas formas. No Modernismo acentua-se o gosto pelos neologismos derivados e compostos, chegando-se ao auge com Guimarães Rosa. (MARTINS, 2000, p. 113).

Deparamo-nos, porém, com essas criações lexicais fora do ambiente da literatura, mas com as mesmas funções poéticas: como recursos expressivos da linguagem. Mesmo que, em seu ambiente original, elas não tenham valor para a literatura, seus propósitos estão intimamente ligados com a significação global do discurso no qual estão inseridas. Como dissemos, vemos que Carro Velho e Odorico Paraguaçu têm as mesmas intenções ao pronunciar essas palavras difíceis: enriquecer o discurso e passar a ideia de dominantes de uma fala de prestígio. O humor está na forma exagerada de fazê-lo. 


\section{O Ensino da Gramática na Sala de Aula}

Após a publicação da primeira lei de Diretrizes e Bases da Educação Nacional, Lei no 4.024/1961, ocorreram modificações significativas no ensino do português no Brasil (SOARES, 2004), que se tornou disciplina obrigatória e exigiu do currículo escolar principal relevo ao seu ensino. $\mathrm{O}$ acesso à escola deixava de ser exclusivo da burguesia para permitir que os filhos dos trabalhadores tivessem oportunidade de alfabetização. Com diferentes realidades e linguagens na sala de aula, esperava-se que a reformulação dos conteúdos para o ensino da língua atendesse a essa inclusão. No entanto, as mudanças se dão apenas na metodologia de ensino:

É então que gramática e texto, estudo sobre a língua e estudo da língua começam a constituir realmente uma disciplina com um conteúdo articulado: ora é na gramática que se vão buscar elementos para a compreensão e a interpretação do texto, ora é no texto que se vão buscar as estruturas lingüísticas para a aprendizagem da gramática (SOARES, 2004, p. 166).

Os manuais passam a incluir exercícios - de vocabulário, de interpretação, de redação, de gramática - mas a língua estudada era "uma só", não havia espaço para o estudo das variações que podem ocorrer e que, em qualquer tempo, podem ser facilmente percebidas dentro ou fora da sala de aula. Enfim, mesmo com as primeiras reflexões sobre o ensino da língua, esta, na escola, ainda não correspondia a uma ferramenta de expressividade na interação social.

Até meados de 1996, o ensino escolar de língua materna no Brasil se encaixava "num período em que ensinar gramática era algo obsoleto e inoperante" (SOUZA; ARÃO, 2009, p. 71). A maioria das obras se refere a esse período como uma época de memorização mecânica de regras gramaticais ou das características de determinado movimento literário. Os pensamentos sobre isso acabaram por se refletir nos Parâmetros Curriculares Nacionais - Português para os anos do Ensino Fundamental:

O que deve ser ensinado não responde às imposições de organização clássica de conteúdos na gramática escolar, mas aos aspectos que 
precisam ser tematizados em função das necessidades apresentadas pelos alunos nas atividades de produção, leitura e escuta de textos. (BRASIL, 1998, p. 29).

E nos Parâmetros Curriculares Nacionais - Português para o Ensino Médio, que ditam que o ensino da língua portuguesa, hoje, deve

... desenvolver no aluno seu potencial crítico, sua percepção das múltiplas possibilidades de expressão lingüística, sua capacitação como leitor efetivo dos mais diversos textos representativos de nossa cultura. [...] $\mathrm{O}$ aluno deve ter meios para ampliar e articular conhecimentos e competências que possam ser mobilizadas nas inúmeras situações de uso da língua com que se depara, na família, entre amigos, na escola, no mundo do trabalho. (BRASIL, 2000, p. 55).

Aumentam, então, a partir de 1996, as propostas de um trabalho com textos na sala de aula, orais ou escritos, pois se percebeu que essa era a forma de atender as necessidades do aluno quanto ao seu desenvolvimento linguístico, para que, consequentemente, esse domínio linguístico contribua para a sua formação como cidadão. Tal propósito implica o acesso à diversidade de usos da língua, com especial atenção à variedade padrão e aos gêneros textuais do domínio público, que a exigem, condição necessária ao aprendizado permanente e à inserção social. Assim, observa-se que a formação do leitor e do produtor de textos está intimamente ligada às práticas discursivas, pois elas não se manifestam apenas por meio de modelos "prontos", antecipados, mas exigem esforço cognitivo e interação social para que a comunicação se estabeleça.

No entanto, ainda é comum nos depararmos, na sala de aula, com análises gramaticais que se restringem à configuração morfológica e/ou função sintática das palavras. Poucas são as iniciativas, inclusive nos livros didáticos de português, em ressaltar a importância do sentido, por meio de fatores sociais e culturais, levando em conta as diversas construções morfológicas, sintáticas, lexicais e discursivas permitidas na interação entre sujeito, língua e mundo. 
Casos como a produção discursiva de Carro Velho ainda são tratados como "aberrações". A ideia de que uma produção discursiva possa prescindir de conteúdo referencial e, ainda assim, alcançar sucesso e prestígio em ambiente social, sequer é considerada. O fato de que um pobre vendedor de leite de porta em porta tenha conseguido uma posição prestigiosa de radialista e apresentador de programas e comerciais regionais de TV por meio de um discurso muito elaborado estilisticamente não é objeto de estudo. A liberdade criativa do falante e as possibilidades infinitas de interação linguística são proscritas em benefício de padrões pré-estabelecidos de pouco valor prático e baixa significatividade para os alunos, especialmente das classes populares. Enfim, nosso ensino brasileiro de língua materna ainda está muito distante da realidade linguística do país. E isso não apenas socioculturamente falando, mas, recorrendo ironicamente à fala de Cipro Neto, "cientificamente" falando também.

\section{Considerações Finais}

A análise do discurso de Carro Velho permite concluir que há uma infinitude de representações de natureza social e cultural na língua além das representações referenciais. Entender "representação" apenas como a alusão a objetos metafísicos é destituir de sua grandeza original a ideia de que a língua é um sistema de representações.

Por meio da língua, são representadas imagens sociais, valores e marcadores de status que vão muito além do conteúdo referencial expresso ou ocultado. Isso faz parte do processo comunicativo, é um fenômeno discursivo e está à frente de questões meramente estilísticas.

Importa que a escola se dê conta disso e consiga fazer essa percepção adentrar a sala de aula. Enfatizamos que essa postura não implica o abandono de práticas escolares que estimulem a ampliação de competência dos alunos centrada na valorização do sentido, critério não considerado por Carro Velho.

Enxergar a língua de um ponto de vista que extrapole sua constituição estruturo-gramatical é essencial para a consecução de um ensino de língua que seja mais do que informativo: que seja realmente formativo e libertador. 


\section{Anexo 1}

Alô, alô, Carlinho Elói e ouvintes da 104! Aqui quem fala é seu amigo Carro Velho. Quero parabenizarmos pelo seu magnífico pogamas e pogama lídel em audiência, um pogama que vem levantano os ouvinte de Quixeramobim. Um, uma, um, uma pessoa que está fazeno o maior sucesso em Quixeramobim. Uma pessoa subjestivamente qualificado, uma pessoa medíocrático, uma pessoa retombante, uma pessoa cabriocárica! São pessoas que vieram de nada e hoje num tem porra ninhuma também! São pessoas que vive fazeno um trabalho magnífico com a sua omilidade, a sua simpricidade, dento da consequência mediováigel. Quero cumprimentar meu amigo Carlinho Elói por ser uma pessoa inoxidável, quer dizer, uma pessoa brilhante! São pessoas estrambólicas! Quero parabenizar por ele ser uma pessoa rélpis, uma pessoa batráquio, pessoa que tenta alegrar a população do nosso Quixeramobim. Quero parabenizá toda famia Balbino, principalmente meu amigo Miguel Balbino, por ser uma pessoa estrogonoficamente sensíuvel, uma pessoa que merece o respeito tecnológico, uma pessoa que vem também dar a sua contribuição aqui no Quixeramobim. E hoje quero parabenizá porque ele criou seu filho, educô e hoje tão ai, fazeno nada por ele! Muito obrigado! ${ }^{11}$

\section{Referências}

BAGNO, M. A lingua de Eulália: novela sociolingüística. São Paulo:

Contexto, 1997.

BASÍLIO, M. Teoria lexical. 8. ed. São Paulo: Ática, 2007.

BOURDIEU, P. A economia das trocas lingüisticas. São Paulo: EDUSP, 1998.

BRAIT, B. Leituras, significações, efeitos de sentido. Líbero (FACASPER), São Paulo, v. 6, n. 11, p. 36-43, 2003.

${ }^{11}$ Texto adaptado do áudio disponível em: < http:/ / migre.me/qHe1e>. Acesso em: 11 dez 2013. 
BRASIL. Ministério da Educação. Secretaria da Educação Fundamental. Parâmetros Curriculares Nacionais: $5^{\mathrm{a}}$ a $8^{\mathrm{a}}$ série do Ensino Fundamental Língua Portuguesa. Brasília: MEC/SEF, 1998.

BRASIL. Ministério da Educação. Secretaria de Educação Média e Tecnológica Semtec. Parâmetros Curriculares Nacionais para o Ensino Médio: Parte II - Linguagens Códigos e suas Tecnologias. Brasília: MEC/Semtec, 2000.

CALVET, L. Sociolingüística: uma introdução crítica. São Paulo: Parábola, 2002.

CARDOSO, E. A. A criação neológica estilística. Matraga, Rio de Janeiro, a. 11, n. 16, 147-162, 2004.

CIPRO NETO, P. "pobrema” e "renegerar". Alô Escola - Nossa Língua Portuguesa. Rotacismo. [s.d.]. Disponível em: <http://migre.me/ qHdUp>. Acesso em: 1 ago. 2013.

EPSTEIN, I. Gramática do poder. São Paulo: Ática, 1993.

FERRAREZI JR., C. Introdução à Semântica de contextos e cenários: de la langue à la vie. Campinas: Mercado de Letras, 2010.

GIL, B. D. Aspectos ideológicos nas escolhas lexicais de Bezerra da Silva. In: ENCONTRO NACIONAL DE INTERAÇÃO EM LINGUAGEM VERBAL E NÃO-VERBAL / SIMPÓSIO INTERNACIONAL DE ANÁLISE CRÍTICA DO DISCURSO, 8. / 2., 2007, São Paulo. Anais... 2007.

GOMES, D. O Bem-Amado. Rio de Janeiro: Ediouro, 1992.

MARTINS, N. S. Introdução à estilística: a expressividade na língua portuguesa. 3. ed. São Paulo: T. A. Queiroz, 2000.

POSSENTI, S. Os humores da língua. Campinas: Mercado de Letras, 1998.

SAUSSURE, F. Escritos de Linguistica Geral. São Paulo: Cultrix, 2012. 
SEARLE, J. R. Os actos de fala - um ensaio de filosofia da linguagem. Coimbra: Almedina, 1991.

SILVA, A. S. O mundo dos sentidos em português: polissemia, semântica e cognição. Coimbra: Almedina, 2006a.

SILVA, N. A construção do estigma em migrantes lusófonos no século XXI. Millenium, Viseu, v. 32, p. 296-307, 2006b.

SOARES, M. Concepções de linguagem e o ensino de Língua Portuguesa. In: SOARES, M. Lingua Portuguesa: história, perspectivas, ensino. São Paulo: Educ, 2004. p. 53-60.

SOUZA, D. S. G.; ARÃO, L. A. A contribuição da Linguística no ensino da língua portuguesa no Brasil. Babilonia, Revista Lusófona de Línguas, Culturas e Tradução, v. 6/7, p. 67-78, 2009.

Recebido em: 14/10/2014 Aceito: $21 / 03 / 2015$ 